\title{
Development of Reading Comprehension in Bilingual and Monolingual Children-Effects of Language Exposure
}

\author{
Theodora Papastefanou ${ }^{1, *}$, Theodoros Marinis ${ }^{1,2}$ (D) and Daisy Powell ${ }^{3}$ \\ 1 School of Psychology \& Clinical Language Sciences, University of Reading, Reading RG6 6DZ, UK; \\ t.marinis@uni-konstanz.de \\ 2 Linguistics Department, University of Konstanz, 78464 Konstanz, Germany \\ 3 Institute of Education, University of Reading, Reading RG1 5EX, UK; d.a.powell@reading.ac.uk \\ * Correspondence: t.papastefanou@pgr.reading.ac.uk
}

Citation: Papastefanou, Theodora, Theodoros Marinis, and Daisy Powell. 2021. Development of Reading Comprehension in Bilingual and Monolingual Children-Effects of Language Exposure. Languages 6: 166. https://doi.org/10.3390/ languages6040166

Academic Editors: Juana M. Liceras and Raquel Fernández Fuertes

Received: 12 February 2021

Accepted: 14 September 2021

Published: 12 October 2021

Publisher's Note: MDPI stays neutral with regard to jurisdictional claims in published maps and institutional affiliations.

Copyright: (c) 2021 by the authors. Licensee MDPI, Basel, Switzerland. This article is an open access article distributed under the terms and conditions of the Creative Commons Attribution (CC BY) license (https:// creativecommons.org/licenses/by/ $4.0 /)$.

\begin{abstract}
The current study aimed at investigating the performance of bilingual children with English as an additional language (EAL) on language and literacy measures compared to monolinguals across the first four years of primary school in the U.K. Moreover, it addressed whether bilinguals and monolinguals' performance on reading comprehension was consistent with the Simple View of Reading. An additional area of interest was to examine the extent to which use of and exposure to both heritage and majority language affected the development of the children's reading comprehension in both of their spoken languages. A total of forty bilingual and forty monolingual children were assessed in oral language skills and decoding in Year 1 and Year 3 in primary school. After one school year, they were assessed in oral language skills, decoding, and reading comprehension in Year 2 and Year 4 . The results showed that the bilinguals performed better than the monolinguals in decoding in all years, suggesting that exposure to a first language with transparent orthography (Greek) may benefit the development of word reading skills. However, the bilinguals scored lower in oral language skills and reading comprehension than their monolingual peers. This finding underlined the significant role of oral language skills in the development of bilinguals' reading comprehension. Both oral language skills and decoding contributed to reading comprehension in bilinguals but the effects of oral language skills on reading comprehension were stronger than the effects of decoding. Finally, we found that language use of the minority language outside the home could significantly predict reading comprehension in the minority language, underlining the importance of language exposure through complementary schools and other activities outside the home to the maintenance and development of the heritage language.
\end{abstract}

Keywords: reading comprehension; English as a second language; decoding; oral language skills; language exposure

\section{Introduction}

Recent statistics from the Department for Education have indicated that $20.2 \%$ of children in U.K. primary schools are learning English as an additional language (EAL) (Statistics at Department for Education 2019). These children have to sufficiently acquire the majority language as it is the language of school instruction. It is also essential for the bilingual children to maintain their heritage language not only because of cultural reasons but because of the benefits that it may have on their majority language and literacy development (Bayram and Wright 2016; Montrul 2016).

The ability to comprehend text is one of the most demanding skills to acquire and also is centrally important for academic achievement (Cain et al. 2004). Reading comprehension is a key to educational attainment, as the learning process in almost all school subjects is based on the ability to understand written text (Mancilla-Martinez and Lesaux 2010). Therefore, investigating the factors that affect reading comprehension, specifically in 
bilingual children, is essential, as teachers could identify the underlying skills that need more focus in the classroom.

The present study aims to examine how primary school Greek-English bilingual children living in the U.K. who acquire Greek as a minority language and English as a majority language perform on several domains of language and reading skills compared to monolinguals in the first four years of primary school. Moreover, the Simple View of Reading (SVR; Gough et al. 1996; Gough and Tunmer 1986; Hoover and Gough 1990) has been repeatedly shown to be a good framework for understanding English monolingual reading development (Kendeou et al. 2009; Oakhill and Cain 2012), but it has less often been applied to bilingual reading development (Goodwin et al. 2015; Proctor et al. 2005). Thus, our study aims to assess the degree to which the SVR (Gough and Tunmer 1986; Hoover and Gough 1990) can account for bilingual (Babayiğit 2014; Proctor et al. 2005) as well as monolingual reading development. Additionally, our study takes into account the transparency and cross-language transfer, which could impact how children approach reading text (Perfetti and Dunlap 2008). Moreover, our study aims to assess whether the contextual/environmental factors, such as language use in and outside the home, parents self-rated language proficiency, and educational level in each separate language, could affect reading comprehension in bilingual children. Specifically, we examined whether the heritage and the majority language input and exposure have an impact on the development of reading comprehension in the children's spoken languages. In what follows, we first introduce the SVR (Gough and Tunmer 1986; Hoover and Gough 1990) that provides a framework regarding the underlying skills of learning to read. Then, we review research on monolingual and bilingual children, examining the relationships between oral language and decoding skills and reading comprehension and how the contextual factors affect bilinguals' reading comprehension in each separate language.

Overall, our study aims to provide evidence about the extent to which the SVR (Gough and Tunmer 1986; Hoover and Gough 1990) can account for bilinguals' as well as to monolinguals' reading development (Babayiğit 2014; Babayiğit and Shapiro 2020; Frid and Friesen 2020; Geva and Farnia 2012; Goodwin et al. 2015). Specifically, the findings of this study will add to existing evidence on how bilinguals' knowledge of two languages with different levels of orthographic transparency, Greek and English, approach reading comprehension (Bonifacci and Tobia 2017; Tobia and Bonifacci 2015). In addition, our study is one of the few studies considering the effects of contextual and environmental factors on reading comprehension in both heritage and majority languages (Howard et al. 2014; Peets et al. 2019). Importantly, our study aims to shed light on the effects of bilingual exposure on children's reading comprehension during the crucial period of reading development.

\subsection{The Simple View of Reading}

Reading comprehension requires the ability to decode written text and knowledge of the words' meanings and sentence level understanding. A very well-known theoretical framework of reading comprehension is the SVR (Gough and Tunmer 1986; Hoover and Gough 1990). The SVR illustrates that reading comprehension is the result of decoding and linguistic comprehension. Joshi and Aaron (2000) pointed out that both decoding and linguistic comprehension are essential for successful reading comprehension. Therefore, readers with difficulties in either decoding skills or linguistic comprehension, or both, may have poor reading comprehension skills (Catts et al. 2006). Developing decoding skills (i.e., word reading and pseudo-word reading) requires multiple processes and skills such as phonological awareness, orthographic symbol knowledge (knowledge of names and sounds of alphabet letters), orthographic awareness, morphological awareness, and rapid automatized naming (Apel et al. 2012; Barker et al. 1992; Burgess and Lonigan 1998; Carlisle 2004; Carlisle and Katz 2006; Kim and Quinn 2013). Decoding skills also encompass both alphabetic decoding and accessing stored knowledge of orthography, the written forms of words (Castles and Nation 2010; Goswami and Bryant 1990). Linguistic comprehension, according to the SVR, is a broad construct that includes "parsing, bridging, 
and discourse building" (Hoover and Gough 1990, p. 128), and "the ability to take lexical information ... and derive sentence and discourse interpretations" (Hoover and Gough 1990, p. 131; see also Tunmer and Chapman 2012). Previous studies have measured linguistic comprehension in several ways, including vocabulary (Ouellette 2006; Ouellette and Beers 2010), listening comprehension (Joshi et al. 2012; Lee et al. 2009; Ouellette and Beers 2010) or combinations of these (Foorman et al. 2015; Kendeou et al. 2009; Protopapas et al. 2012).

Several cross-sectional studies investigating the SVR have demonstrated a developmental shift in terms of the contributions of decoding and linguistic comprehension to reading comprehension as a function of both text difficulty and readers skill level (Catts et al. 2005; Gough et al. 1996). Thus, decoding skills can significantly contribute to reading comprehension for younger children, but this can change over time as once children have developed adequate decoding, linguistic comprehension skills appear to become the best predictors of reading comprehension. On the other hand, longitudinal studies on bilinguals are rare (Droop and Verhoeven 2003; Nakamoto et al. 2007), but they are essential, as they provide evidence about how reading comprehension develops. Such studies could shed light on the difference between the development rate of reading comprehension of bilinguals and monolinguals and the effects of decoding and oral language skills on reading comprehension. Our study aims to provide evidence in terms of the influence of decoding and oral language skills on the development of reading comprehension in bilingual relative to monolingual children.

Lesaux, Siegel, and colleagues ran a series of large-scale studies and found that English-speaking Canadian L1 and L2 learners performed similarly on the measures of reading comprehension (Lesaux et al. 2006, 2007; Lesaux and Siegel 2003). For example, Lesaux et al. (2007) examined children from kindergarten to the fourth grade and reported that first language (L1) and second language (L2) groups scored at comparative levels on reading comprehension and their language development was quite similar. These results are in contrast to later studies (Lervåg and Aukrust 2010). The longitudinal studies to date addressing the development of reading comprehension skills in bilingual children are few in number and although their findings are important, the picture emerging is incomplete. For example, Droop and Verhoeven (2003) addressed reading comprehension of Dutch as a majority language in the Netherlands and demonstrated that both decoding and oral language skills of Dutch in third grade predicted later reading comprehension of Dutch, a patttern which is similar to the pattern attested in monolingual children. In addition, Nakamoto et al. (2007) investigated reading comprehension of English as a majority language in the USA and showed that difficulties in oral language skills in the English were negatively associated with the development of reading comprehension in English.

In summary, existing longitudinal studies have provided some evidence about how reading comprehension develops over time in bilingual children, but more research is needed to establish the predictors of development in reading comprehension skills in bilingual children. It is also worth noting that the majority of these studies have not considered the effects of contextual/environmental factors (Lipka et al. 2005) that can contribute to individual differences in bilingual children. Thus, our study will provide evidence not only on the contributions of decoding and oral language skills to bilinguals' reading comprehension, it will also examine the effects of language use and exposure to each of the children's spoken languages.

\subsection{Reading Comprehension in Monolingual and Bilingual Children}

The fact that reading comprehension in monolingual children is mainly based on decoding skills and linguistic comprehension has been confirmed in various studies (Catts et al. 2006; Chen and Vellutino 1997; Geva and Farnia 2012; Johnston and Kirby 2006; Kendeou et al. 2009; Nation and Snowling 2004). An additional factor that should be taken into account when reading development is examined is the level of the orthographic 
consistency in the languages tested. Alphabetic languages differ in the consistency of the mappings between symbols and sounds. For example, Italian has a highly transparent orthography, where there is a one-to-one relationship between graphemes and phonemes. English, on the other hand, has an opaque orthography, with many inconsistent words with unpredictable spellings (e.g., yacht, through). Orthographic consistency may affect reading development across grades; for example, the rate of acquisition has been shown to be faster in the relatively transparent vowelized Hebrew orthography than in English, although Hebrew was the minority language (Geva and Siegel 2000). Geva and Siegel's (2000) study illustrated that the development of early reading skills in bilinguals may proceed faster in languages with transparent orthographies than in languages with opaque orthographies. This aligns with cross-linguistic comparisons of reading development in monolingual children which show different trajectories based on orthographic transparency (Seymour et al. 2003).

In terms of the SVR, it has been demonstrated that the role of decoding and language comprehension in predicting reading comprehension varies in relation to the level of the orthographic transparency. For example, studies examining less transparent languages (e.g., English) have shown that the influence of oral language skills on reading comprehension gradually increases over the school years (Florit and Cain 2011). On the other hand, studies run on more transparent orthographies, such as Norwegian, Greek, and Dutch, emphasized that oral language skills contribute more significantly to early reading development than decoding skills (de Jong and van der Leij 2002; Hagtvet 2003; Protopapas et al. 2007). Bonifacci and Tobia (2017) conducted a study involving students learning Italian (transparent orthography) as a second language. The results showed that listening comprehension was the most powerful predictor of reading comprehension performance in those children. In addition, reading accuracy showed a smaller but still significant influence in the group of younger children attending the first two years of primary school, but it was not a significant predictor in the older group. These results are partially in contrast with previous findings demonstrating a main role of decoding in the first few years of schooling for transparent orthographies (Florit and Cain 2011) in monolingual children. However, these results accord with studies conducted on children acquiring English as an L2, in which a significant contribution of listening comprehension was found to reading comprehension (Babayiğit 2014; Proctor et al. 2005).

The relationship between word reading, oral language skills and reading comprehension in bilingual children has been examined in depth, focusing on only one of the children's language, namely their majority language (Bonifacci and Tobia 2017; Hoover and Gough 1990; Proctor et al. 2005). Group comparisons generally show that bilinguals tend to perform poorly compared to their monolingual peers on measures of reading comprehension (see Melby-Lervåg and Lervåg 2014). Several studies have examined the predictors of reading comprehension in monolingual and bilingual children in their majority language. For example, Babayiğit (2015) compared the strength of the associations between decoding, oral language skills and reading comprehension in monolingual and bilingual children who were developing literacy in English. The results revealed that the effect of oral language skills on reading comprehension was high in both groups, although there was evidence for a stronger relationship between the two skills in the bilinguals. Similarly, Verhoeven (2000) and Verhoeven and Van Leeuwe (2012) demonstrated that the predictors were the same in monolinguals and bilinguals (in their majority language), but oral language skills were more strongly associated with reading comprehension in the bilinguals than the monolinguals. Additionally, Lervåg and Aukrust (2010) reported that low vocabulary knowledge of Norwegian as a majority language in bilingual children in the second grade was the main cause of their poor performance on reading comprehension of Norwegian. Similarly, Babayiğit (2014) demonstrated that older bilingual children with difficulties in oral language skills (i.e., vocabulary and sentence processing skills) in English as their majority language would perform poorly on English reading comprehension over and above the effects of nonverbal reasoning and verbal memory skills. 
It is worth noting that oral language skills, specifically expressive vocabulary, are usually found to be more limited in bilingual children than in monolingual children (Bialystok et al. 2010; Melby-Lervåg and Lervåg 2014). On the contrary, both phonological awareness and word reading skills have been shown to develop similarly in monolinguals and bilinguals and in some cases, bilinguals may perform better than monolinguals in phonological awareness abilities (August and Shanahan 2006; Bialystok et al. 2003, 2005; Chiappe et al. 2002). Therefore, the bilingual children's lower scores on reading comprehension measures have been associated with difficulties in oral language skills (Babayiğit 2015; Burgoyne et al. 2011; Cobo-Lewis et al. 2002; Lervåg and Aukrust 2010; Melby-Lervåg and Lervåg 2014). Indeed, it has been demonstrated that reading comprehension can be at risk if more than $3 \%$ of words in a given text are unknown to the reader (Carver 1994). Hence, the prominent effects of oral language skills on reading comprehension may underline the significant role of oral language skills in the differences between monolinguals and bilinguals in reading comprehension (Melby-Lervåg and Lervåg 2014).

Although a large body of research has examined reading development in bilingual children, only few studies have investigated bilingual children who are able to read and write in both languages (Reyes 2012) and their reading development in both the majority and minority languages. For instance, Leikin et al. (2005) ran a study examining two groups of Russian-Hebrew bilingual children-one monoliterate in Hebrew and one biliterate-and monolingual Hebrew children on several linguistic, metalinguistic and cognitive tasks at the end of the first year of primary school. The results showed that the biliterate bilinguals outperformed the other two groups on fluid intelligence, reading fluency measures in the majority language Hebrew, and phonological awareness tasks. The main differences were in Hebrew receptive vocabulary, working memory, and rapid serial naming. However, the biliterate bilinguals had received literacy instruction (in Russian) earlier than the other two groups (in Hebrew), so a follow-up study was conducted that included an additional Hebrew monolingual group that had acquired basic literacy skills before entering school (Schwartz et al. 2008). The comparison between the biliterate bilinguals and the early-literate Hebrew monolinguals showed that the biliterate bilinguals performed better on eight out of the nine reading measures in Hebrew, although the difference only reached statistical significance for measures of word and pseudoword reading accuracy. Moreover, the biliterate children performed better than the monoliterate bilinguals on Russian measures of phonological awareness, receptive vocabulary, and syntactic awareness. Taken together, the findings from this set of studies suggest that acquiring literacy in the minority language is associated with better oral skills in that same language as well as with benefits for the development of literacy in the majority language, at least during the initial stages. Our study aims to extend the evidence about whether acquiring literacy in the minority language can benefit bilingual children's literacy skills in the majority language.

\subsection{Effects of Contextual Factors on Reading Comprehension}

Language exposure plays a significant role in language development (De Houwer 2009; Gathercole and Thomas 2009; Pearson et al. 1997). For example, bilingual children usually have less exposure to each of the two languages compared to their monolinguals peers and they tend to acquire oral language skills at a slower rate (Hoff et al. 2012). Although there is evidence suggesting that contextual factors (e.g., children's language exposure and proficiency level, parental level of education, parental rating of their own language proficiency) can affect oral language skills (e.g., vocabulary, morphology, complex syntax) (Chondrogianni and Marinis 2011; Duursma et al. 2007; Thordardottir 2011), the relationship between contextual factors and reading comprehension has received less attention (Curdt-Christiansen and La Morgia 2018).

Indeed, there are few studies investigating the possible relationship between home literacy environment and reading comprehension in bilinguals (Howard et al. 2014; Peets et al. 2019). The home literacy environment is generally defined as the context 
and interaction between parents and children around picture books, in terms of reading frequency and number of books in the home and is known to affect reading comprehension in monolingual children (Katzir et al. 2009; Speece et al. 2004; Sénéchal 2006; Van Steensel 2006). By improving reading skills, a stimulating home literacy environment can have a positive impact on monolingual children's reading comprehension (Katzir et al. 2009; Sénéchal 2006; Speece et al. 2004; Van Steensel 2006). Specifically, home literacy activities, such as exposure to a storybook, are indirectly related to reading comprehension by developing children's early language skills, such as vocabulary (Roth et al. 2002; Sénéchal 2006; Sénéchal and LeFevre 2002). In the case of bilingual children, the relationship between this experience and reading comprehension is not clear. There are some studies that have investigated the role of the home literacy environment in the development of bilinguals languages (Chow et al. 2010; Farver et al. 2013; Gonzalez and Uhing 2008), and one that we know involves the role of the mother tongue in reading comprehension. Howard et al. (2014) studied its integration with SES, school language, and vocabulary and literacy practices. They found that family literacy was not prominent at the second-grade level, but it was indeed prominent at the fifth-grade level, predicting $13 \%$ of the changes in reading comprehension. Our study is one of the few studies that longitudinally examines language and reading development of bilingual children in both languages, taking into account the contribution of contextual factors (i.e., language input and exposure inside and outside the home, parents' self-rated language proficiency and educational level) in both Greek and English.

\section{Aims of the Study}

The first aim of the present study was to investigate the performance of bilingual and biliterate children on language and literacy measures in comparison to monolingual peers. The participants were split into two age groups, a younger and an older group (initially in Year 1 and Year 3, respectively, of UK primary school), who were tested two times, one school year apart. The first research question was: did children's performance on language and literacy skills depend on language group (Bilinguals vs. Monolinguals), age (Younger vs. Older children), and time (Time 1 vs. Time 2)? Is there an interaction between those factors? We hypothesized that bilinguals would perform better than monolinguals in English (L2) decoding, as their first language has a transparent orthography, which may help them to develop word reading skills quicker than monolinguals or they would perform at comparable levels with their monolingual peers (Lesaux et al. 2006). However, bilinguals may perform less well than monolinguals in morpho-syntactic skills and reading comprehension, reflecting the role played by differences in oral language proficiency in reading comprehension development (Droop and Verhoeven 2003). The prediction also was that both monolingual and bilingual children's performance would improve as they progress through school.

The second aim of this study was to investigate whether bilinguals' performance on reading comprehension was consistent with the SVR (Gough and Tunmer 1986; Hoover and Gough 1990). The SVR posits that a sufficient development in linguistic comprehension and decoding is necessary to achieve reading comprehension. In addition, it has been well established in the literature that oral language skills and decoding account for unique variance in reading comprehension in monolinguals (Vellutino et al. 2007), but there's been less research on whether this model (SVR) could extend to bilinguals (Kieffer and Vukovic 2012; Lesaux et al. 2010). Thus, the second research question was: could oral language skills and decoding at Time 1 predict reading comprehension at Time 2 separately in bilinguals and monolinguals? We hypothesized that vocabulary and morpho-syntactic skills, aspects of linguistic comprehension, and decoding would contribute to both bilingual and monolingual children's performance on reading comprehension. It was expected that decoding would play a less predictive role than oral language skills in predicting reading comprehension (Droop and Verhoeven 2003; Melby-Lervåg and Lervåg 2014; Verhoeven and Van Leeuwe 2012). Specifically, we hypothesized that oral language skills would make 
stronger contributions to bilinguals' reading comprehension, indicating that difficulties in oral language skills can affect the bilinguals' performance on reading comprehension (Melby-Lervåg and Lervåg 2014; Droop and Verhoeven 2003).

Finally, the third aim of our study was to investigate how a range of contextual factors (e.g., language use and exposure) might affect the development of the children's reading comprehension in the two languages. The third research question was: could the contextual factors predict the bilingual children's performance on reading comprehension in each language? We hypothesized that these contextual factors would contribute positively to the children's performance on reading comprehension, specifically for the minority language (Dickinson and Porche 2011). Specifically, it was predicted that language use inside and outside the home in Greek would be significantly correlated with Greek reading comprehension.

\section{Methodology}

\subsection{Participants}

A total of eighty typically developing children were recruited from primary schools in the London, Reading and Oxford area: forty typically developing Greek-English bilingual children, 20 from Year 1 (Mean age $=76.6$ months, $S D=3.6,14$ boys and 6 girls) and 20 from Year 3 (Mean age $=100.4$ months, $\mathrm{SD}=3.4,9$ boys and 11 girls); forty typically developing English monolingual children, 20 from Year 1 (Mean age $=74.6$ months, $\mathrm{SD}=3.8,7$ boys and 13 girls) and 20 from Year 3 (Mean age $=98.8$ months, $\mathrm{SD}=3.2,14$ boys and 6 girls). All of the children attended English mainstream primary schools and the bilinguals also attended a Greek supplementary school. Most of the bilinguals were born in the U.K. but some were born in Greece and moved to the UK at least 2 years before the commencement of the study. The children came mostly from families of average and above-average socioeconomic status. Moreover, none of them had any history of speech and/or language delay or impairment and their parents were not concerned about their language development.

\subsection{Materials}

The bilingual participants were assessed in both their languages in order to estimate their language and reading skills in both Greek and English. Standardized and non-standardized assessments, as well as experimental tasks, were used to measure the children's non-verbal abilities, vocabulary, morpho-syntactic skills, decoding skills and reading comprehension. The LITMUS-PABIQ questionnaire (Tuller 2015) was used to measure the children's language history. The monolingual participants were assessed in English language and reading skills using the same experimental tasks as in the bilingual group. To be able to compare the children's performance in English and Greek, we included assessments that had parallel versions in the two languages. Full details of the tasks used are given below.

Non-verbal IQ: The children's non-verbal abilities were measured using Raven's Coloured Progressive Matrices Test (Raven et al. 2004). The test was developed to measure general ability in children aged 4 to 11 years in educational and clinical settings. Test-retest reliability was reported as 0.88 for Progressive Matrices. The CPM consists of 36 perceptual and conceptual matching exercises that are divided into three sets of 12 items, whereby the items increase in difficulty within a given set. The raw score is the total number of correct items out of 36 .

Expressive Vocabulary: English vocabulary was measured using the Renfrew Word Finding Vocabulary Scale (Renfrew 1995) and Greek Vocabulary using its Greek adaptation (Vogindroukas et al. 2009). The raw score is the total number of correct items out of 50 for both English and Greek versions. Raw scores were converted to percentages. The test manual does not report the test-retest reliability.

Sentence repetition tasks (S.R.T.): To measure the children's morpho-syntactic skills, a sentence repetition task was administered in both English and Greek (Marinis and ArmonLotem 2015). The task was used to assess different aspects of oral language skills, including 
knowledge and use of syntactic structures, the ability to produce grammatically correct sentences, and listening comprehension.

Both the English and Greek Sentence Repetition Tasks were developed within the COST Action IS080419 (Marinis and Armon-Lotem 2015). In this task, children have to listen to a series of sentences and are asked to repeat them verbatim. The English Sentence Repetition Task (English SRT) comprised 30 sentences that included a range of different grammatical structures. There were six sentences for each sentence type. The Greek Sentence Repetition Task (Greek SRT) was slightly longer and consisted of 32 sentences. There were eight different sentence types in the Greek SRT with four sentences each.

Both English and Greek had the same administration procedure. The sentences were pre-recorded by a native speaker of English and Greek, respectively, and were embedded into a PowerPoint presentation. The task was introduced as a game to the children named "The Treasure Hunt", featuring a bear named Teddy. Children were seated in front of a computer laptop and were given a set of headphones to prevent any noise disruptions. They were told that in order to follow Teddy on his treasure hunt, they had to listen carefully to the sentences and repeat exactly what they hear. Children's responses were voicerecorded and subsequently transcribed for further analyses. Children's responses were scored for overall accuracy, grammaticality and correct use of the target structure. Based on preliminary strong correlations between accuracy, grammaticality and structure in both Greek and English, we transformed these variables into composites scores. The composite score was calculated by converting the raw scores to $\mathrm{z}$ scores, and then taking the mean of $\mathrm{z}$ scores of the tasks. Greek accuracy was significantly correlated with Greek grammaticality $(r=0.592, p<0.01)$ and Greek structure $(r=0.596, p<0.01)$, and Greek grammaticality was significantly correlated with Greek structure $(r=0.718, p<0.01)$. English accuracy significantly correlated with English grammaticality $(r=0.884, p<0.01)$ and English structure $(r=0.848, p<0.01)$, and English grammaticality significantly correlated with English structure $(r=0.873, p<0.01)$. Both English and Greek versions had high reliability, Cronbach's alpha for the Greek task was 0.83, and for the English version was 0.95.

Decoding: English Decoding was assessed using The Test of Word Reading Efficiency (TOWRE) (Torgesen et al. 1999) and Greek Decoding was assessed using the Greek adaption of the TOWRE-2 (Georgiou et al. 2012). The TOWRE (Torgesen et al. 1999) was used to assess the participants' word-level reading skills in English. This test includes two subtests: The Sight Word Efficiency subtest assesses the number of real printed words that can be accurately read within $45 \mathrm{~s}$, and the Phonemic Decoding Efficiency subtest measures the number of pseudo-words that can be accurately decoded within $45 \mathrm{~s}$. The score was the number of words read correctly. Torgesen et al. (1999) reported test-retest reliability of 0.95 for ages 6 to 9 years. For decoding in Greek, we used the adaption of the TOWRE-2 by Georgiou et al. (2012). It consists of 104 words beginning with 1-syllable words and ending with 3-syllable words. However, in Greek the words were relatively longer than in English. Georgiou et al. (2012) reported test-retest reliability of 0.96 for grade four. The score was the number of words read correctly. For the TOWRE-Phonemic Decoding Efficiency subtest, an 8-item practice list was presented first, followed by a list of 63 pseudo-words in three columns (ordered in terms of difficulty). Children were asked to read the pseudowords as quickly as possible. Based on preliminary strong correlations between the two tasks (word reading and non-word reading subtasks) in each language (Time 1: English: $r=0.548, p<0.01$; Greek: $r=0.712, p<0.01$; Time 2: English: $r=0.468, p<0.01$; Greek: $r=0.648, p<0.01$ ), we created composites scores from the two tasks for each language. The composite score was calculated by converting the raw scores to $\mathrm{z}$ scores, and then taking the mean of $\mathrm{z}$ scores of the two tasks. The English tasks had relatively high reliability, Cronbach's a $=0.69$ while Greek tasks had high reliability, Cronbach's a $=0.82$.

Reading comprehension: The primary version of the York Assessment of Reading for Comprehension (Snowling et al. 2009) was used to assess reading comprehension in English. Each passage is followed by eight open-ended oral comprehension questions to which children provide oral answers. The comprehension questions assess both literal 
and inferential comprehension skills and children are free to refer to the passage whilst answering the questions. In terms of Greek reading comprehension, we developed a test similar to YARC using the same testing procedure. The Greek version of the YARC provides a total of 12 passages, two for each grade, with age-appropriate characteristics and gradually increasing in length and readability (Dell'Orletta et al. 2011). Descriptive and narrative passages were provided, and children had to read them aloud. The participants were allowed to look back at the text as the examiner read the questions and children were asked to give open answers orally, which were transcribed by the examiner. For each text, 8 questions were provided. Although the majority of the questions require textbased comprehension processes, and therefore, the child has to consider only information explicitly presented in the passages (local comprehension; Rawson and Kintsch (2005)), some questions require inferential reasoning (global comprehension; Rawson and Kintsch (2005)). The participants had to read two texts in each language.

The Questionnaire for Parents of Bilingual Children (PABIQ; Tuller 2015) was used to obtain data on the children's language history, quantity and quality of input, and use. The LITMUS-PABIQ (Tuller 2015) was developed within COST Action IS0804 based on questionnaires developed in (Paradis 2010, 2011). The questionnaire includes sections on the child's early language history, current language skills, language used at home, languages spoken outside the home and information about the maternal and paternal education and their language proficiency in each language. It also includes sections about how often the child communicates in different languages. Specifically, the LITMUS-PABIQ questionnaire (Tuller 2015) was used in order to measure/operationalize the contextual measures (e.g., language use at home, language use outside home, parental self-language proficiency and education).

\subsection{Procedure}

At both Time 1 and Time 2, children were individually assessed in a quiet room in their schools or homes. The assessments in both testing points were divided into two sessions lasting around $45 \mathrm{~min}$ each. In Time 1, one session consisted of measuring the children's non-verbal IQ, English expressive vocabulary, phonological awareness, and decoding. In this session, the participants' parents completed the LITMUS-PABIQ questionnaire. The other session consisted of the Greek language and literacy tasks. Time 2 assessments followed the same procedure as at Time 1, including reading comprehension assessment in both languages, but children were not retested on their non-verbal abilities and parents did not have to complete the PABIQ for a second time. The second testing point was one school year after the first one. The order of the sessions as well as the order of the tests within each session were counterbalanced. Parental written consent was obtained prior to onset of the data collection.

\section{Results}

4.1. Comparison between the Younger and Older Bilingual Children's Performance on the Two Languages at the Two Testing Points

The first research question addressed if there is a difference between the children's performance on the objective measures of language and word-level reading skills at the two testing points, between the Greek and English tasks and between the two age groups.

Table 1 summarizes younger and older bilingual children's performance on expressive vocabulary, phonological awareness, morphological awareness, and decoding tasks in the two languages at the two testing points. 
Table 1. Descriptive statistics of the bilingual children's performance on the Greek and English expressive vocabulary, morpho-syntax and decoding (real-words, pseudo-word) and reading comprehension tasks (percentage correct) at Time 1 and Time 2.

\begin{tabular}{|c|c|c|c|c|c|c|c|c|c|}
\hline & & \multicolumn{3}{|c|}{ Greek } & \multicolumn{4}{|c|}{ English } & \multirow{3}{*}{$\begin{array}{c}\text { T2: } \\
\text { Older }\end{array}$} \\
\hline & & T1: & T1: & $\mathrm{T} 2:$ & T2: & T1: & T1: & T2: & \\
\hline & & Younger & Older & Younger & Older & Younger & Older & Younger & \\
\hline \multirow{3}{*}{ Expressive vocabulary } & Mean & 58.1 & 73.8 & 65.1 & 79.7 & 76.4 & 87.6 & 80.2 & 91.4 \\
\hline & SD & 8.55 & 12.73 & 8.23 & 12.59 & 9.33 & 9.96 & 7.5 & 7.23 \\
\hline & Min-Max & $42-70$ & 50-94 & $50-76$ & $56-98$ & $66-100$ & $70-100$ & 70-94 & $74-100$ \\
\hline \multirow[t]{3}{*}{ Morpho-syntactic skills } & Mean & 28.12 & 46.49 & 37.64 & 56.22 & 44.2 & 58.28 & 49.87 & 64.37 \\
\hline & SD & 10.9 & 10.2 & 13.9 & 7.5 & 5.1 & 8.5 & 4.7 & 5.9 \\
\hline & Min-Max & $16-54$ & $22-58$ & $27-52$ & $37-65$ & $36-53$ & $41-70$ & $41-56$ & $50-72$ \\
\hline \multirow[t]{3}{*}{ Decoding } & Mean & 52.93 & 77.27 & 58.79 & 81.12 & 67.76 & 83.68 & 72.03 & 86.86 \\
\hline & SD & 19.13 & 14.66 & 17.73 & 14.59 & 12.1 & 4.74 & 8.66 & 4.68 \\
\hline & Min-Max & $27-85$ & $34-96$ & $32-89$ & 41-98 & $41-88$ & $72-90$ & $58-87$ & 74-93 \\
\hline \multirow[t]{3}{*}{ Reading Comprehension } & Mean & - & - & 24.69 & 52.81 & - & - & 45.53 & 67.39 \\
\hline & SD & - & - & 6.6 & 10.63 & - & - & 9.36 & 13.48 \\
\hline & Min-Max & - & - & $13-31$ & $31-69$ & - & - & $31-68$ & $42-86$ \\
\hline
\end{tabular}

“T1" = Time 1, “T2" = Time 2.

\section{Expressive vocabulary}

To examine differences between the Age groups, between Greek and English, and between Time of testing, we entered the results (in percentages correct) into repeatedmeasures ANOVAs with Age group (younger, older) as the between participants factor, Language (Greek, English) and Time (Time 1, Time 2) as the within participants factors, for each separate task. The analysis of the expressive vocabulary tasks showed a significant main effect of Time $\left(F(1,38)=30.87, p<0.001, \eta_{p}{ }^{2}=0.448\right)$, a significant main effect of Language $\left(F(1,38)=85.61, p<0.001, \eta_{p}{ }^{2}=0.693\right)$, and significant Language by Age $\left(F(1,38)=10.52, p=0.002, \eta_{p}^{2}=0.217\right)$, Time by Language interaction $(F(1,38)=257.29$, $\left.p<0.001, \eta_{p}{ }^{2}=0.867\right)$, and Time by Language by Age Interactions $(F(1,38)=10.57, p=0.002$, $\eta_{p}{ }^{2}=0.566$ ). To explore the 3-way interaction, we split the file based on Age (younger vs. older) and we looked at the 2-way interaction between Language and Time. The analysis for the Younger group showed a significant main effect of Time $(F(1,19)=48.43$, $\left.p<0.001, \eta_{p}{ }^{2}=0.718\right)$, a significant main effect of Language $(F(1,19)=42.63, p<0.001$, $\left.\eta_{p}{ }^{2}=0.692\right)$, and a significant interaction between Language and Time $(F(1,19)=4.49$, $\left.p<0.05, \eta_{p}{ }^{2}=0.191\right)$. The results of the Older group showed a significant main effect of Time $\left(F(1,19)=8.41, p=0.009, \eta_{p}^{2}=0.306\right)$, a significant main effect of Language $\left(F(1,19)=45.31, p<0.001, \eta_{p}{ }^{2}=0.704\right)$, but the interaction between Language and Time was not significant $(F(1,19)=0.518, p=\mathrm{ns}$.). To explore the significant interaction in the Younger group we run simple effects tests. Both at Time 1 and Time 2, children were better in English than Greek (Time 1: $F(1,19)=47.59, p<0.001, \eta_{p}{ }^{2}=0.715$; Time 2: $\left.F(1,19)=31.72, p<0.001, \eta_{p}{ }^{2}=0.625\right)$. The children's performance was significantly better at Time 2 than at Time 1 in both languages (Greek: $F(1,19)=27.87, p<0.001, \eta_{p}{ }^{2}=0.595$; English: $\left.F(1,19)=24.58, p<0.001, \eta_{p}{ }^{2}=0.564\right)$. The interaction is likely to have resulted from the larger effect size in the difference between English and Greek at Time 1 (0.715) compared to Time 2 (0.625), suggesting that the difference between Greek and English in Time 1 is smaller than in Time 2.

\section{Morpho-syntactic skills}

The analysis of the morpho-syntactic tasks showed a significant main effect of Time $\left(F(1,38)=427.007, p<0.001, \eta_{p}{ }^{2}=0.918\right)$, a significant main effect of Language $(F(1$, $\left.38)=47.32, p<0.001, \eta_{p}^{2}=0.555\right)$, and a significant main effect of Age $(F(1,38)=86.95$, $\left.p<0.001, \eta_{p}{ }^{2}=0.696\right)$. Although the Time by Age, the Language by Age and the Time by Language by Age interactions were not significant $(F(1,38)=0.221, p=0.641$, $F(1,38)=1.41, p=n s$ and $F(1,38)=0.009, p=n s$ respectively $)$, the Language by Time was significant $\left(F(1,38)=0.233, p<0.001, \eta_{p}^{2}=0.380\right)$.

The Time by Language interaction was analysed using simple effects tests. The tests demonstrated that children were better at Time 2 compared to Time 1 in both Greek and 
English (Greek: $F(1,38)=49.391, p<0.001, \eta_{p}{ }^{2}=0.565$; English: $F(1,38)=41.313, p<0.001$, $\left.\eta_{p}{ }^{2}=0.521\right)$. The children performed better in English than Greek both at Time 1 and Time 2 (Time 1: $F(1,38)=271.98, p<0.001, \eta_{p}{ }^{2}=0.877$; Time $2: F(1,38)=146.367$, $\left.p<0.001, \eta_{p}{ }^{2}=0.794\right)$. The interaction is likely to have resulted from the larger effect size in the difference between English and Greek at Time 1 (0.877) compared to Time 2 (0.794), suggesting that the difference between Greek and English in Time 1 is smaller than in Time 2.

\section{Decoding}

The analysis of the decoding tasks showed a significant main effect of Time $(F(1,38)=$ $\left.42.01, p<0.001, \eta_{p}{ }^{2}=0.526\right)$, a significant main effect of Language $(F(1,38)=21.52, p<0.001$, $\left.\eta_{p}{ }^{2}=0.362\right)$, and a significant main effect of Age $\left(F(1,38)=32.25, p<0.001, \eta_{p}{ }^{2}=0.459\right)$. The Time by Age, the Language by Age, the Language by Time, and the Time by Language by Age interactions were not significant $(F(1,38)=1.37, p=0.249, F(1,38)=3.38, p=0.074$, $F(1,38)=0.771, p=n s$, and $F(1,38)=0.126, p=n s$ respectively) suggesting that both younger and older children had higher scores in Time 2 than in Time 1 and achieved higher scores in English than Greek.

\section{Reading comprehension}

There was a significant main effect of Age, favoring older children $(F(1,38)=112.7$, $\left.p<0.001, \eta_{p}^{2}=0.748\right)$, a significant main effect of Language, indicating that bilinguals performed better in English than $\operatorname{Greek}\left(F(1,38)=61.58, p<0.001, \eta_{p}{ }^{2}=0.618\right)$. The interaction between Age and Language was not significant $(F(1,38)=1.93, p=n s)$.

4.2. Comparison between the Bilingual and Monolingual Children's Performance on English Language Tasks Based on Their Age (Younger vs. Older), and Two Testing Points (Time 1 vs. Time 2)

Table 2 summarizes the bilingual and monolingual children's performance in English based on age and testing time.

Table 2. Descriptive statistics of the younger and older bilinguals and their monolingual peers' performance on the Raven's Coloured Progressive Matrices and the English expressive vocabulary, morpho-syntax and decoding (real-words, pseudo-word) and reading comprehension tasks (percentage correct) across the four years of primary school in the U.K.

\begin{tabular}{|c|c|c|c|c|c|c|c|c|c|}
\hline & & \multicolumn{4}{|c|}{ Bilinguals } & \multicolumn{4}{|c|}{ Monolinguals } \\
\hline & & T1: & T1: & T2: & T2: & T1: & T1: & T2: & T2: \\
\hline & & Younger & Older & Younger & Older & Younger & Older & Younger & Older \\
\hline \multirow{3}{*}{ Raven's } & Mean & 30.95 & 29.9 & - & - & 27.15 & 31.40 & - & - \\
\hline & SD & 3.45 & 2.95 & - & - & 3.17 & 2.85 & - & - \\
\hline & Min-Max & $25-30$ & $26-34$ & - & - & $21-32$ & $25-35$ & - & - \\
\hline \multirow[t]{3}{*}{ Expressive vocabulary } & Mean & 76.4 & 87.6 & 80.2 & 91.4 & 79 & 89.1 & 83.5 & 92.8 \\
\hline & $\mathrm{SD}$ & 9.33 & 9.95 & 7.48 & 7.23 & 4.07 & 8.27 & 5.15 & 5.56 \\
\hline & Min-Max & $66-100$ & $70-100$ & $70-94$ & $74-100$ & $68-85$ & $76-100$ & $74-94$ & $82-100$ \\
\hline \multirow[t]{3}{*}{ Morpho-syntactic skills } & Mean & 44.2 & 58.28 & 49.87 & 64.37 & 47.36 & 62.96 & 54.06 & 70.37 \\
\hline & $\mathrm{SD}$ & 5.1 & 8.54 & 4.67 & 5.89 & 7.12 & 6.16 & 5.99 & 5.29 \\
\hline & Min-Max & $36-53$ & $41-70$ & $41-56$ & $50-72$ & $37-63$ & $50-76$ & $43-65$ & $51-77$ \\
\hline \multirow[t]{3}{*}{ Decoding } & Mean & 67.76 & 83.68 & 72.03 & 86.86 & 63.23 & 83.11 & 66.67 & 84.88 \\
\hline & $\mathrm{SD}$ & 12.1 & 4.74 & 8.66 & 4.68 & 14.7 & 6.87 & 6.86 & 3.92 \\
\hline & Min-Max & $41-88$ & $72-90$ & $58-87$ & 74-93 & $37-89$ & $68-93$ & $50-78$ & 75-90 \\
\hline \multirow[t]{3}{*}{ Reading Comprehension } & Mean & - & - & 45.53 & 67.39 & - & - & 56.95 & 77.35 \\
\hline & $\mathrm{SD}$ & - & - & 9.36 & 13.49 & - & - & 16.32 & 13.59 \\
\hline & Min-Max & - & - & $31-68$ & $42-86$ & - & - & $31-84$ & $45-100$ \\
\hline
\end{tabular}

"T1" = Time 1, "T2" = Time 2.

Table 2 gives an overview of the bilingual and monolingual children's raw scores on the Raven's Coloured Progressive Matrices ( $n, M$, SD, range). The descriptive statistics suggest relatively equal performance by the two groups on the Raven's. To examine whether there are group differences on non-verbal abilities, we run the ANCOVA with age as covariate. The analysis revealed no group differences on Raven's raw scores $(F(1,77)=1.78$, $p=n s$ ) confirming that the two groups (bilinguals and monolinguals) were well matched on non-verbal IQ. 
To examine the differences between bilinguals and monolinguals between Age groups and between Times of testing, we entered the results into three-way mixed ANOVAs with Age group (Younger vs. Older) and Group (Bilinguals vs. Monolinguals) as the between participants factors and Time (Time 1 vs. Time 2) as the within participants factor, for expressive vocabulary, morpho-syntactic skills and decoding separately. For reading comprehension, as data were only available at Time 2, a two-way ANOVA was run to examine the differences between Language group (Bilinguals vs. Monolinguals) on reading comprehension and Age (Younger vs. Older).

\section{English expressive vocabulary}

There was a significant main effect of Time, favoring Time $2(F(1,76)=22.54, p<0.001$, $\left.\eta_{p}{ }^{2}=0.229\right)$ and a significant main effect of Age, favoring older children $(F(1,76)=53.37$, $\left.p<0.001, \eta_{p}{ }^{2}=0.413\right)$. However, there was a non-significant main effect of Group, indicating that bilinguals and monolinguals did not differ from each other $(F(1,76)=2.31, p=n s)$ and there were no significant interactions between Time and Group $(F(1,76)=0.023, p=n s)$, Time by Age $(F(1,76)=0.059, p=n s)$; Group by Age $(F(1,76)=0.275, p=n s)$; Time by Age by $\operatorname{Group}(F(1,76)=0.059, p=n s)$.

\section{English morpho-syntactic skills}

There was a significant main effect of Time, favoring Time $2(F(1,76)=174.45, p<0.001$, $\left.\eta_{p}{ }^{2}=0.697\right)$, a significant main effect of Group, favoring monolinguals $(F(1,76)=12.05$, $\left.p<0.001, \eta_{p}{ }^{2}=0.137\right)$, and a significant main effect of Age, favoring older children $\left(F(1,76)=135.66, p<0.001, \eta_{p}^{2}=0.642\right)$. The interactions were not significant: Time by Age $(F(1,76)=0.338, p=n s)$; Time by Group $(F(1,76)=1.43, p=n s)$; Group by Age $(F(1,76)=0.414, p=n s ;$ Time by Age by Group $(F(1,76)=0.021, p=n s)$.

\section{English decoding}

There was a significant main effect of Time, favoring Time $2(F(1,76)=9.28, p=0.003$, $\left.\eta_{p}{ }^{2}=109\right)$, a significant main effect of Group, favoring bilinguals, $(F(1,76)=3.71, p<0.05$, $\left.\eta_{p}{ }^{2}=0.046\right)$, and a significant effect of Age, favoring older children $(F(1,76)=113.50$, $\left.p<0.001, \eta_{p}{ }^{2}=0.599\right)$. None of the interactions were significant: Time by $\operatorname{Group}(F(1,76)=$ $0.290, p=n s)$; Time by Age $(F(1,76)=0.443, p=n s) ; \operatorname{Age~by~Group~}(F(1,76)=0.020, p=n s)$ Time by Age by Group $(F(1,76)=0.051, p=n s)$.

\section{English reading comprehension}

There was a significant main effect of Age, favoring older children $(F(1,79)=49.26$, $\left.p<0.001, \eta_{p}{ }^{2}=0.396\right)$, a significant main effect of Group, favoring monolinguals $(F(1,79)=$ $\left.12.61, p<0.001, \eta_{p}{ }^{2}=0.144\right)$. The interaction between Age and Group was not significant $(F(1,79)=0.059, p=n s)$.

To summarize the findings so far, the children performed better on all tasks at Time 2 than Time 1 and the older children performed better than the younger ones. Monolinguals outperformed bilinguals on morpho-syntactic and reading comprehension skills. However, the monolinguals and the bilinguals did not significantly differ from each other on vocabulary. On the other hand, bilinguals scored better on decoding than monolinguals.

\subsection{Relationship between Oral Language Skills and Decoding at Time 1 and Reading Comprehension at Time 2 Separately in Bilinguals and Monolinguals}

The second research question addressed whether oral language skills and decoding at Time 1 could separately predict reading comprehension at Time 2 in bilinguals and monolinguals. The hypothesis was that vocabulary and morpho-syntactic skills, aspects of linguistic comprehension, and also decoding, would contribute to both bilingual and monolingual children's performance on reading comprehension. A composite score for expressive vocabulary and morpho-syntactic skills was calculated by calculating percentage correct for each task and using the mean of the $\mathrm{z}$ scores for the two tasks. To address this question, we used multiple linear regressions. In each case, only those variables yielding significant bivariate correlations with the criterion variable were included in the regression.

\section{Correlations}

Tables 3 and 4 shows the simple correlations between all variables (above the diagonal) and partial correlations controlling for age (below the diagonal). Variables were 
residualized for age (Durand et al. 2005) because of the small sample size of the children and the broad age range and also because previous research has indicated that some of the relationships under investigation vary with age. This avoided adding an additional variable to the regression models to avoid further inflating the ratio of variables to participants in the analysis. The pattern of relations in the partial correlations is weaker than, but generally similar to, the pattern in the simple correlations.

Table 3. Correlations between bilingual children's performance on English decoding and oral language skills in Time 1 and reading comprehension in Time 2, with zero order correlations above the diagonal, and correlations between age-controlled variables below the diagonal.

\begin{tabular}{lccc}
\hline & $\mathbf{1}$ & $\mathbf{2}$ & $\mathbf{3}$ \\
\hline 1. Decoding & & $0.59^{* *}$ & $0.56^{* *}$ \\
2. Oral language skills & $0.54^{* *}$ & - & $0.61^{* *}$ \\
3. Reading Comprehension & $0.51^{*}$ & $0.64^{* *}$ & - \\
\hline
\end{tabular}

** Correlation is significant at the 0.01 level (2-tailed). ${ }^{*}$ Correlation is significant at the 0.05 level (2-tailed).

Table 4. Correlations between monolingual children's performance on English decoding and oral language skills in Time 1 and reading comprehension in Time 2, with zero order correlations above the diagonal, and correlations between age-controlled variables below the diagonal.

\begin{tabular}{lccc}
\hline & $\mathbf{1}$ & $\mathbf{2}$ & $\mathbf{3}$ \\
\hline 1. Decoding & - & $0.63^{* *}$ & $0.46^{* *}$ \\
2. Oral language skills & $0.59^{* *}$ & - & $0.53^{* *}$ \\
3. Reading Comprehension & $0.48^{*}$ & $0.59^{*}$ & - \\
\hline$* *$ Correlation is significant at the 0.01 level (2-tailed). ${ }^{*}$ Correlation is significant at the 0.05 level (2-tailed).
\end{tabular}

The analysis revealed that oral language skills and decoding significantly correlated with reading comprehension in both bilinguals and monolinguals. It is worth noting that the effect sizes for decoding and oral language skills in relation to reading comprehension were larger in bilinguals than in monolinguals.

\section{Regressions}

The main focus of the second question was to address whether the bilingual children's data, as well as that of monolinguals, are consistent with the SVR by looking at the contribution of the two dimensions of the SVR, decoding and oral language skills, to reading comprehension in both monolingual and bilingual groups.

Regression analysis: predictors of English reading comprehension in Bilinguals

A standard multiple regression was performed on English reading comprehension at Time 2 as the dependent variable and English decoding and oral language skills at Time 1 as the independent variables. Prior to the analysis, the data were screened to ensure that the assumptions were met. The results are summarized in Table 5, which shows that the regression model was significant, and that English decoding and oral language skills were significant predictors of English reading comprehension, suggesting that bilingual children were consistent with the SVR.

Table 5. Summary of multiple regression analysis for variables predicting bilingual children's reading comprehension performance in English $(N=40)$.

\begin{tabular}{cccc}
\hline \multirow{2}{*}{ Variables } & \multicolumn{3}{c}{ English Reading Comprehension.2 } \\
\cline { 2 - 4 } & B & SE B & $\beta$ \\
\hline Decoding.Eng.1 & 0.347 & 0.93 & $0.264^{*}$ \\
Oral language skills.Eng.1 & 5.09 & 1.6 & $0.470^{* *}$ \\
$R^{2}$ & & 0.324 & \\
$F$ & & $13.36^{* *}$ & \\
${ }^{* *}$ Correlation is significant at the 0.01 level (2-tailed). ${ }^{*}$ Correlation is significant at the 0.05 level (2-tailed).
\end{tabular}




\section{Regression analysis: predictors of English reading comprehension in Monolinguals}

A standard multiple regression was performed on English reading comprehension at Time 2 as the dependent variable and English decoding and oral language skills at Time 1 as the independent variables. Prior to the analysis the data were screened to ensure that the assumptions were met. The results are summarized in Table 6, which shows that the regression model was significant, and that English decoding and oral language skills were significant predictors of English reading comprehension in monolinguals.

Table 6. Summary of multiple regression analysis for variables predicting monolingual children's reading comprehension performance in English $(N=40)$.

\begin{tabular}{|c|c|c|c|}
\hline \multirow{2}{*}{ Variables } & \multicolumn{3}{|c|}{ English Reading Comprehension.2 } \\
\hline & B & SE B & $\beta$ \\
\hline Decoding.Eng.1 & 0.287 & 0.178 & 0.197 * \\
\hline Oral language skills.Eng.1 & 7.05 & 2.58 & $0.435^{* *}$ \\
\hline$R^{2}$ & 0.267 & & \\
\hline$F$ & $8.26^{* * *}$ & & \\
\hline
\end{tabular}

4.4. Contextual Factors as Predictors of Bilingual Children's Reading Comprehension Performance in Each Language Separately

The third question addressed whether the parental report measures of children's language exposure and proficiency level, parental level of education, parental rating of their own language proficiency could predict the objective measures of children's reading comprehension in Greek and English separately. Prior to the regression analysis, Pearson's correlations were carried out, as shown in Tables 7 and 8.

Table 7. Correlation matrix for children's performance on reading comprehension and language use in and outside home, parents' self-rated language proficiency and parents' educational level in Greek.

\begin{tabular}{lcccc}
\hline & $\mathbf{1 .}$ & $\mathbf{2 .}$ & $\mathbf{3 .}$ & $\mathbf{4 .}$ \\
\hline 1 Language use in home & - & & & \\
2. Language use outside home & $0.71^{* *}$ & - & & \\
3. Parental Educational Level & 0.13 & 0.23 & - & - \\
4. Parental Proficiency Level & 0.19 & 0.28 & 0.14 & - \\
5. Reading Comprehension & $0.43^{* *}$ & $0.65^{* *}$ & 0.04 & 0.30 \\
\hline${ }^{* *}$ Correlation is significant at the 0.01 level (2-tailed). & & &
\end{tabular}

Table 8. Correlation matrix for children's performance on reading comprehension and language use in and outside home, parents' self-rated language proficiency and parents' educational level in English.

\begin{tabular}{lcccc}
\hline & $\mathbf{1 .}$ & $\mathbf{2 .}$ & $\mathbf{3 .}$ & $\mathbf{4 .}$ \\
\hline 1. Language use in home & - & & & \\
2. Language use outside home & 0.12 & - & & \\
3. Parental Educational Level & 0.31 & 0.19 & - & - \\
4. Parental Proficiency Level & 0.02 & 0.01 & 0.16 & 0.24 \\
5.Reading Comprehension & 0.05 & 0.28 & 0.08 & \\
\hline
\end{tabular}

The analysis revealed that overall, the bilingual children's performance on the Greek reading comprehension task was significantly positively correlated with Greek language use inside and outside the home. On the other hand, there were no significant relationships between the contextual factors and children's performance on the English reading 
comprehension task, indicating that exposure to and use of Greek had no negative effects on children's reading comprehension in English.

A standard multiple regression analysis was performed on Greek reading comprehension at Time 2 as the dependent variable and Greek language use inside and outside the home at Time 1 as the independent variables. Prior to the analysis, the data was screened to ensure that the assumptions underlying the use of regression analysis were met. The results are summarized in Table 9, which shows that the regression model was significant, and that Greek language use outside the home was a significant predictor of Greek reading comprehension.

Table 9. Summary of multiple regression analysis for contextual variables predicting children's performance on reading comprehension in Greek $(\mathrm{N}=40)$.

\begin{tabular}{cccc}
\hline \multirow{2}{*}{ Variable } & \multicolumn{3}{c}{ Greek Reading Comprehension } \\
\cline { 2 - 4 } & B & SE B & $\beta$ \\
\hline Language use in home & 0.609 & 1.53 & 0.070 \\
Language use outside the home & 5.1 & 1.26 & $0.703^{* * *}$ \\
$R^{2}$ & & 0.412 & \\
$F$ & & $13.92^{* * *}$ & \\
\hline
\end{tabular}

${ }_{* * *}$ Correlation is significant at the 0.001 level (2-tailed).

\section{Discussion}

\subsection{Comparing Bilinguals and Monolinguals' Language and Reading Skills}

The first research question addressed whether there are differences in the development of several domains of oral language and reading skills between Group (bilinguals vs. monolinguals), Age (Younger vs. Older) and Testing time (Time 1 vs. Time 2). The results showed that bilinguals performed better in decoding skills compared to monolinguals. This is in line with previous research suggesting that bilingual children may develop decoding skills with a similar rate or even faster than monolinguals (August and Shanahan 2006; Bialystok et al. 2003, 2005; Chiappe et al. 2002). In addition, the bilingual children involved in our study speak two languages that differ in terms of their orthographic transparency. Greek has a very transparent orthography, whereas English has an opaque orthography. This can have implications on how easily and quickly these children develop their decoding skills, which may affect positively reading comprehension in an opaque language such as English. Taking this into account, the results could suggest that reading instruction and/or learning to read in a language with a transparent orthography (Greek) may benefit literacy development of a language with an opaque orthography (English). However, it should be acknowledged that we have not directly tested whether it was the transparent nature of the Greek orthography that had this effect, rather than just the fact the children were exposed to another language. Therefore, the data cannot provide evidence for a causal relationship between orthographic transparency and literacy development.

On the other hand, our findings demonstrated that the bilinguals scored lower in morpho-syntactic skills and reading comprehension than their monolingual peers. This finding is consistent with previous findings suggesting that bilingual children may perform lower than monolingual children in oral language skills and reading comprehension (Bialystok et al. 2010; Melby-Lervåg and Lervåg 2014). Indeed, various studies have shown that difficulties in oral language skills have been associated with bilinguals' lower performance in reading comprehension (Babayiğit 2015; Burgoyne et al. 2011; Cobo-Lewis et al. 2002; Lervåg and Aukrust 2010; Melby-Lervåg and Lervåg 2014). Therefore, it is expected that oral language skills will have much bigger effects on the reading comprehension of bilinguals than they will for monolinguals (Melby-Lervåg and Lervåg 2014).

\subsection{Simple View of Reading in Bilinguals and Monolinguals}

The second research question addressed whether the SVR (Gough and Tunmer 1986; Hoover and Gough 1990) can account for bilingual as well as monolingual reading develop- 
ment (Proctor et al. 2005; Oakhill and Cain 2012; Goodwin et al. 2015) and whether there is a difference between bilinguals and monolinguals in terms of the relative contribution of oral language and decoding skills to reading comprehension. The results showed that both oral language and decoding skills at Time 1 contributed to reading comprehension at Time 2 in both the bilinguals and the monolinguals. Importantly, Verhoeven and Van Leeuwe (2012) have demonstrated that decoding skills (i.e., reading speed) were always a significant predictor of reading comprehension from first to sixth grade of primary school. Additionally, we found that the effects of oral language skills were relatively stronger in bilinguals than monolinguals. Similarly, Babayiğit (2015) examined the strength of the relationships between decoding, oral language skills and reading comprehension in monolingual and bilingual children who were developing literacy in English. The results illustrated that the effect of oral language skills on reading comprehension was high in both groups, but the relationship between the two skills was much stronger in the bilinguals. Indeed, in spite of their stronger decoding skills, the bilingual children performed less well in reading comprehension, indicating that linguistic comprehension must make a stronger contribution to reading comprehension in this group than in their monolingual peers. Thus, the relationship between oral language skills and reading comprehension could be the main cause of bilinguals' lower performance in reading comprehension (Lervåg and Aukrust 2010; Babayiğit 2014).

With regards to the SVR, our study showed that oral language skills and decoding predicted bilinguals and monolinguals' reading comprehension. This aligns with previous studies (Proctor et al. 2005; Goodwin et al. 2015), demonstrating that the SVR is a reliable model in explaining the development of reading comprehension in bilingual children. For example, Goodwin et al. (2015) pointed out that there were similarities in the way that reading subcomponents affect reading comprehension in both bilinguals' spoken languages. In addition, Goodwin et al. (2015) demonstrated that oral language skills play a larger role than decoding in reading comprehension performance in both children's languages. Similarly, Proctor et al. (2005) suggested that the SVR was proven to be a reliable starting point for a model framework of L2 reading comprehension. In addition, Proctor et al. (2005) reported that oral language skills were much more strongly associated with reading comprehension than decoding in bilinguals. Taken together, our study provides further evidence that the SVR (Gough and Tunmer 1986; Hoover and Gough 1990) can account for bilingual as well as monolingual reading development, and also, we showed that the role of oral language skills in the development of reading comprehension is particularly significant in this bilingual group. This finding has implications for teachers' pedagogical strategies as it suggests the importance of providing more intensive oral language skills intervention for their bilingual students (Proctor et al. 2005).

The limited longitudinal studies comparing the development of reading comprehension skills in bilinguals and monolinguals have shown inconsistent results. For example, some of these studies have demonstrated that both decoding and oral language skills are associated with reading comprehension and reported a similar development rate of reading comprehension in bilinguals and monolinguals (Droop and Verhoeven 2003; Lesaux et al. 2007). On the other hand, Lervåg and Aukrust (2010) illustrated the significant role of vocabulary in the development of L2 reading comprehension. Specifically, Lervåg and Aukrust's (2010) study showed that bilinguals developed their reading comprehension skills more slowly than their monolingual peers. This finding suggests that bilinguals may score lower than their monolingual peers in reading comprehension in spite of mastering decoding skills (Nakamoto et al. 2007). Our findings are consistent with Nakamoto et al. (2007) and Lervåg and Aukrust (2010) studies showing that lower oral language skills can be the cause of the slower development in bilinguals' reading comprehension compared to monolinguals. 


\subsection{Effects of Contextual Factors on Reading Comprehension}

The third research question examined whether language use and exposure can affect reading comprehension in both the heritage and the majority language. Our results showed that heritage language use outside the home contributed to the bilinguals' reading comprehension in Greek. This aligns with previous studies (Dickinson and Tabors 2001), suggesting that exposure to heritage language is a significant factor to the bilinguals' L2 reading development. In addition, the participants of our study attended the Greek complimentary school, and thus, they were receiving Greek language and reading instruction. Indeed, Dickinson and Porche (2011) demonstrated that schooling in the heritage language is positively associated with children's oral language and reading skills in that language. On the other hand, although there was a correlation between heritage language use in the home and reading comprehension in Greek, heritage language use inside the home was not a significant predictor of bilinguals' Greek reading comprehension. This may seem surprising in the first instance because previous research stressed that home literacy activities could benefit and enrich literacy development in children's heritage language (Curdt-Christiansen and La Morgia 2018). However, it is unclear to what extent the families in our sample used home literacy activities. What is clear is that children attended the Greek complimentary school where they received Greek reading instruction which explains the contribution of language use outside the home to Greek reading comprehension.

With regards to English, we did not find any significant relationship between the language use and exposure and reading comprehension. This can be explained by the fact that bilinguals receive plenty of exposure to English through formal schooling, and thus, their parents tend to promote the use of Greek language inside and outside the home.

\subsection{Implications/Future Directions}

The finding that the effect sizes of oral language skills were stronger for the development of reading comprehension in the bilinguals than the monolinguals suggests that bilingual children should be supported in developing their oral language skills (e.g., vocabulary and morpho-syntactic skills) from an early age. Future studies should shed light on whether early intervention to oral language skills can promote reading comprehension. For example, Bowyer-Crane et al. (2008) demonstrated that children with difficulties in oral language skills at the beginning of school who received an intervention based on oral language showed better performance on measures of vocabulary. In addition, Aukrust (2007) reported that the qualities of vocabulary used by teachers in preschool children could predict second language skills (e.g., vocabulary). Therefore, while some evidence exists concerning the significant role of instructional approaches to oral language skills, future studies should address more comprehensive approaches to promoting oral language skills learning in both bilinguals and monolinguals.

\section{Conclusions}

This study is one of few studies examining the development of bilingual children's performance on language and reading skills in relation to their monolingual peers, taking into account the effects of language exposure and use. Our study aimed to investigate the performance of bilingual children on language and literacy measures compared to monolinguals. We were interested in language and reading development across the first four years of primary school in the U.K. Specifically, our study explored the differences in the development of reading comprehension between the bilinguals and their monolingual peers. The results showed that the bilinguals performed better in decoding compared to the monolinguals, suggesting that learning to read in a first language with transparent orthography (Greek) may benefit the development of word reading skills in L2 (Lesaux et al. 2006). However, the bilinguals scored lower in English (L2) oral language skills and reading comprehension than their monolingual peers. This finding stresses the significant role of oral language skills to the development of bilinguals' reading comprehension (Droop and Verhoeven 2003). With regards to whether bilinguals and monolinguals' performance on 
reading comprehension was consistent with the Simple View of Reading (SVR) (Gough and Tunmer 1986; Hoover and Gough 1990), we found that both oral language skills and decoding significantly correlated with reading comprehension in bilinguals, and the effect of oral language skills was stronger than that of decoding (Melby-Lervåg and Lervåg 2014). Finally, our study examined how Greek and English language use and exposure could affect the development of the children's reading comprehension in both of their spoken languages. We found that language use outside the home predicted reading comprehension in the heritage language, illustrating the importance of exposure to the heritage language through complementary schools and other activities outside the home for its maintenance and development (Dickinson and Porche 2011). Crucially, there was no evidence of negative effects of exposure to Greek on English reading and linguistic comprehension.

Author Contributions: Conceptualization, T.P., T.M. and D.P.; methodology, T.P., T.M. and D.P.; validation, T.P., T.M. and D.P.; formal analysis, T.P.; investigation, T.P., T.M. and D.P.; data curation, T.P., T.M. and D.P.; writing-original draft preparation, T.P.; writing-review and editing, T.P., T.M. and D.P.; visualization, T.P.; supervision, T.M. and D.P. All authors have read and agreed to the published version of the manuscript.

Funding: This research received no external funding.

Institutional Review Board Statement: The study has been reviewed by the Research Ethics Committee of the School of Psychology and Clinical Language Sciences at the University of Reading and has been given a favorable ethical opinion for conduct (ethics application number: 2016-217-TM). All of the investigators on this project have had criminal records checks and have been approved to work with children.

Informed Consent Statement: Informed consent was obtained from all participants' parents/guardians involved in the study.

Data Availability Statement: Data will be published online at UoR depository.

Conflicts of Interest: The authors declare no conflict of interest.

\section{References}

Apel, Kenn, Elizabeth B.Wilson-Fowler, Danielle Brimo, and Nancy A. Perrin. 2012. Metalinguistic contributions to reading and spelling in second and third grade students. Reading and Writing 25: 1283-305. [CrossRef]

August, Diane, and Timothy Shanahan. 2006. Synthesis: Instruction and professional development. In Developing Literacy in Second-Language Learners. Mahwah: Lawrence Erlbaum Associates, pp. 351-64.

Aukrust, Vibeke Grøver. 2007. Young children acquiring second language vocabulary in preschool group-time: Does amount, diversity, and discourse complexity of teacher talk matter? Journal of Research in Childhood Education 22: 17-37. [CrossRef]

Babayiğit, Selma. 2014. The role of oral language skills in reading and listening comprehension of text: A comparison of monolingual (L1) and bilingual (L2) speakers of English language. Journal of Research in Reading 37: S22-47. [CrossRef]

Babayiğit, Selma. 2015. The relations between word reading, oral language, and reading comprehension in children who speak English as a first (L1) and second language (L2): A multigroup structural analysis. Reading and Writing 28: 527-44. [CrossRef]

Babayiğit, Selma, and Laura Shapiro. 2020. Component skills that underpin listening comprehension and reading comprehension in learners with English as first and additional language. Journal of Research in Reading 43: 78-97. [CrossRef]

Barker, Theodore A., Joseph K Torgesen, and Richard K. Wagner. 1992. The role of orthographic processing skills on five different reading tasks. Reading Research Quarterly 27: 335-45. [CrossRef]

Bayram, Fatih, and Clare Wright. 2016. Turkish Heritage Language Acquisition and Maintenance in Germany. In Handbook of Research and Practice in Heritage Language Education. Cham: Springer, pp. 2-18.

Bialystok, Ellen, Catherine McBride-Chang, and Gigi Luk. 2005. Bilingualism, language proficiency, and learning to read in two writing systems. Journal of Educational Psychology 97: 580. [CrossRef]

Bialystok, Ellen, Gigi Luk, Kathleen F. Peets, and Sujin Yang. 2010. Receptive Vocabulary Differences in Monolingual and Bilingual Children. Bilingualism: Language and Cognition 13: 525-31. [CrossRef] [PubMed]

Bialystok, Ellen, Shilpi Majumder, and Michelle M. Martin. 2003. Developing phonological awareness: Is there a bilingual advantage? Applied Psycholinguistics 24: 27-44. [CrossRef]

Bowyer-Crane, Snowling Claudine, Margaret J. Duff, Fiona J. Fieldsend, Elizabeth Carroll, Julia M. Miles, and Jeremy Charles Hulme. 2008. Improving early language and literacy skills: Differential effects of an oral language versus a phonology with reading intervention. Journal of Child Psychology and Psychiatry 49: 422-32. [CrossRef] [PubMed] 
Bonifacci, Paola, and Valentina Tobia. 2017. The simple view of reading in bilingual language-minority children acquiring a highly transparent second language. Scientific Studies of Reading 21: 109-19. [CrossRef]

Burgess, Stephen R., and Christopher J. Lonigan. 1998. Bidirectional relations of phonological sensitivity and prereading abilities: Evidence from a preschool sample. Journal of Experimental Child Psychology 70: 117-41. [CrossRef]

Burgoyne, Kelly, H. E. Whiteley, and Jane Margaret Hutchinson. 2011. The development of comprehension and reading-related skills in children learning English as an additional language and their monolingual, English-speaking peers. British Journal of Educational Psychology 81: 344-54. [CrossRef]

Cain, Kate, Jane Oakhill, and Peter Bryant. 2004. Children's reading comprehension ability: Concurrent prediction by working memory, verbal ability, and component skills. Journal of Educational Psychology 96: 31. [CrossRef]

Carlisle, Joanne F. 2004. Morphological processes that influence learning to read. Handbook of Language and Literacy: Development and Disorders 1: 318-39.

Carlisle, Joanne F., and Lauren A. Katz. 2006. Effects of word and morpheme familiarity on reading of derived words. Reading and Writing 19: 669-93. [CrossRef]

Carver, Ronald P. 1994. Percentage of unknown vocabulary words in text as a function of the relative difficulty of the text: Implications for instruction. Journal of Reading Behavior 26: 413-37. [CrossRef]

Castles, Anne, and Kate Nation. 2010. How does Orthographic Learning Happen? In From Inkmarks to Ideas. New York: Psychology Press, pp. 181-209.

Catts, Hugh W., Suzanne M. Adlof, and Susan Ellis Weismer. 2006. Language deficits in poor comprehenders: A case for the simple view of reading. Journal of Speech, Language, and Hearing Research 49: 278-93. [CrossRef]

Catts, Hugh W., Tiffany P. Hogan, and Suzanne M. Adlof. 2005. Developmental Changes in Reading and Reading Disabilities. In The Connections between Language and Reading Disabilities. New York: Psychology Press, pp. 38-51.

Chen, Ru San, and Frank R. Vellutino. 1997. Prediction of reading ability: A cross-validation study of the simple view of reading. Journal of Literacy Research 29: 1-24. [CrossRef]

Chiappe, Penny, Linda S. Siegel, and Alexandra Gottardo. 2002. Reading-related skills of kindergartners from diverse linguistic backgrounds. Applied Psycholinguistics 23: 95-116. [CrossRef]

Chondrogianni, Vasiliki, and Theodoros Marinis. 2011. Differential effects of internal and external factors on the development of vocabulary, tense morphology and morpho-syntax in successive bilingual children. Linguistic Approaches to Bilingualism 1: 318-45. [CrossRef]

Chow, Bonnie Wing-Yin, Catherine McBride-Chang, and Him Cheung. 2010. Parent-child reading in English as a second language: Effects on language and literacy development of Chinese kindergarteners. Journal of Research in Reading 33: 284-301. [CrossRef]

Cobo-Lewis, A. B., B. Z. Pearson, R. E. Eilers, and V. C. Umbel. 2002. Effects of Bilingualism and Bilingual Education on Oral and Written English Skills: A Multifactor Study of Standardized Test Outcomes; Inderdependance of Spanish and English Knowledge in Language and Literacy among Bilingual English Children. In Language and Literacy in Bilingual Children. Clevedon: Multilingual Matters.

Curdt-Christiansen, Xiao Lan, and Francesca La Morgia. 2018. Managing heritage language development: Opportunities and challenges for Chinese, Italian and Pakistani Urdu-speaking families in the UK. Multilingua 37: 177-200. [CrossRef]

De Houwer, Annick. 2009. An Introduction to Bilingual Development. Bristol: Multilingual Matters.

de Jong, Peter F., and Aryan van der Leij. 2002. Effects of phonological abilities and linguistic comprehension on the development of reading. Scientific studies of Reading 6: 51-77. [CrossRef]

Dell'Orletta, Felice, Simonetta Montemagni, and Giulia Venturi. 2011. READ-IT: Assessing Readability of Italian Texts with a View to Text Simplification. Paper present at the Second Workshop on Speech and Language Processing for Assistive Technologies, Edinburgh, UK, July 30; pp. 73-83.

Dickinson, David K., and Michelle V. Porche. 2011. Relation between language experiences in preschool classrooms and children's kindergarten and fourth-grade language and reading abilities. Child Development 82: 870-86. [CrossRef]

Dickinson, David K., and Patton O. Tabors. 2001. Beginning Literacy with Language: Young Children Learning at Home and School. Baltimore: Paul H Brookes Publishing.

Droop, Mienke, and Ludo Verhoeven. 2003. Language proficiency and reading ability in first-and second-language learners. Reading Research Quarterly 38: 78-103. [CrossRef]

Durand, Marianne, Charles Hulme, Rebecca Larkin, and Margaret Snowling. 2005. The cognitive foundations of reading and arithmetic skills in 7-to 10-year-olds. Journal of Experimental Child Psychology 91: 113-36. [CrossRef]

Duursma, Elisabeth, Silvia Romero-Contreras, Anna Szuber, Patrick Proctor, Catherine Snow, Diane August, and Margarita Calderón. 2007. The role of home literacy and on bilinguals' English and Spanish vocabulary development. Applied Psycholinguistics 28: 171-90. [CrossRef]

Farver, Jo Ann M., Yiyuan Xu, Christopher J. Lonigan, and Stefanie Eppe. 2013. The home literacy environment and Latino head start children's emergent literacy skills. Developmental Psychology 49: 775. [CrossRef]

Florit, Elena, and Kate Cain. 2011. The simple view of reading: Is it valid for different types of alphabetic orthographies? Educational Psychology Review 23: 553-76. [CrossRef] 
Foorman, Barbara R., Sarah Herrera, Yaacov Petscher, Alison Mitchell, and Adrea Truckenmiller. 2015. The structure of oral language and reading and their relation to comprehension in kindergarten through grade 2. Reading and writing 28: 655-81. [CrossRef] [PubMed]

Frid, Bailey, and Deanna C. Friesen. 2020. Reading comprehension and strategy use in fourth-and fifth-grade French immersion students. Reading and Writing 33: 1213-33. [CrossRef]

Gathercole, Virginia C. Mueller, and Enlli Môn Thomas. 2009. Bilingual first-language development: Dominant language takeover, threatened minority language take-up. Bilingualism: Language and Cognition 12: 213-37. [CrossRef]

Georgiou, George, Timothy C. Papadopoulos, Elena Zarouna, and Rauno Parrila. 2012. Are auditory and visual processing deficits related to developmental dyslexia? Dyslexia 18: 110-29. [CrossRef] [PubMed]

Geva, Esther, and Fataneh Farnia. 2012. Developmental changes in the nature of language proficiency and reading fluency paint a more complex view of reading comprehension in ELL and EL1. Reading and Writing 25: 1819-45. [CrossRef]

Geva, Esther, and Linda S. Siegel. 2000. Orthographic and cognitive factors in the concurrent development of basic reading skills in two languages. Reading and Writing 12: 1-30. [CrossRef]

Gonzalez, Jorge E., and Brad M. Uhing. 2008. Home literacy environments and young Hispanic children's English and Spanish oral language: A communality analysis. Journal of Early Intervention 30: 116-39. [CrossRef]

Goodwin, Amanda P., Diane August, and Margarita Calderon. 2015. Reading in multiple orthographies: Differences and similarities in reading in Spanish and English for English Learners. Language Learning 65: 596-630. [CrossRef]

Goswami, Usha, and Peter Bryant. 1990. Phonological Skills and Learning to Read. New York: Psychology Press.

Gough, P., W. Hoover, and C. Peterson. 1996. Some Observations on a Simple View of Reading. In Reading Comprehension Difficulties: Processes and Intervention. Mahwah: Lawrence Erlbaum Associates, pp. 1-13.

Gough, Philip B., and William E. Tunmer. 1986. Decoding, reading, and reading disability. Remedial and Special Education 7: 6-10. [CrossRef]

Hagtvet, Bente E. 2003. Listening Comprehension and reading comprehension in poor decoders: Evidence for the importance of syntactic and semantic skills as well as phonological skills. Reading and Writing 16: 505-39. [CrossRef]

Hoff, Erika, Cynthia Core, Silvia Place, Rosario Rumiche, Melissa Señor, and Marisol Parra. 2012. Dual language exposure and early bilingual development. Journal of Child Language 39: 1-27. [CrossRef] [PubMed]

Hoover, Wesley A., and Philip B. Gough. 1990. The simple view of reading. Reading and Writing 2: 127-60. [CrossRef]

Howard, Elizabeth R., Mariela M. Páez, Diane L. August, Christopher D. Barr, Dorry Kenyon, and Valerie Malabonga. 2014. The importance of SES, home and school language and literacy practices, and oral vocabulary in bilingual children's English reading development. Bilingual Research Journal 37: 120-41. [CrossRef]

Johnston, Timothy C., and John R. Kirby. 2006. The contribution of naming speed to the simple view of reading. Reading and Writing 19: 339-61. [CrossRef]

Joshi, R. Malatesha, and P. G. Aaron. 2000. The component model of reading: Simple view of reading made a little more complex. Reading Psychology 21: 85-97.

Joshi, R. Malatesha, Sha Tao, P. G. Aaron, and Blanca Quiroz. 2012. Cognitive component of componential model of reading applied to different orthographies. Journal of Learning Disabilities 45: 480-86. [CrossRef] [PubMed]

Katzir, Tami, Nonie K. Lesaux, and Young-Suk Kim. 2009. The role of reading self-concept and home literacy practices in fourth grade reading comprehension. Reading and Writing 22: 261-76. [CrossRef]

Kendeou, Panayiota, Paul Van den Broek, Mary Jane White, and Julie S. Lynch. 2009. Predicting reading comprehension in early elementary school: The independent contributions of oral language and decoding skills. Journal of Educational Psychology $101: 765$. [CrossRef]

Kieffer, Michael J., and Rose K. Vukovic. 2012. Components and context: Exploring sources of reading difficulties for language minority learners and native English speakers in urban schools. Journal of Learning Disabilities 45: 433-52. [CrossRef]

Kim, James S., and David M. Quinn. 2013. The effects of summer reading on low-income children's literacy achievement from kindergarten to grade 8: A meta-analysis of classroom and home interventions. Review of Educational Research 83: 386-431. [CrossRef]

Lee, Lay Wah, Kevin Wheldall, Robyn Beaman, and Alison Madelaine. 2009. A conceptual framework for remedial reading instruction for low-progress early readers in Malaysian. Asia Pacific Journal of Speech, Language and Hearing 12: 57-70. [CrossRef]

Leikin, Mark, David L. Share, and Mila Schwartz. 2005. Difficulties in L2 Hebrew reading in Russian-speaking second graders. Reading and Writing 18: 455-72. [CrossRef]

Lervåg, Arne, and Vibeke Grøver Aukrust. 2010. Vocabulary knowledge is a critical determinant of the difference in reading comprehension growth between first and second language learners. Journal of Child Psychology and Psychiatry 51: 612-20. [CrossRef]

Lesaux, Nonie K., and Linda S. Siegel. 2003. The development of reading in children who speak English as a second language. Developmental Psychology 39: 1005. [CrossRef] [PubMed]

Lesaux, Nonie K., Orly Lipka, and Linda S. Siegel. 2006. Investigating cognitive and linguistic abilities that influence the reading comprehension skills of children from diverse linguistic backgrounds. Reading and Writing 19: 99-131. [CrossRef]

Lesaux, Nonie K., Andre A. Rupp, and Linda S. Siegel. 2007. Growth in reading skills of children from diverse linguistic backgrounds: Findings from a 5-year longitudinal study. Journal of Educational Psychology 99: 821. [CrossRef] 
Lesaux, Nonie K., Amy C. Crosson, Michael J. Kieffer, and Margaret Pierce. 2010. Uneven profiles: Language minority learners' word reading, vocabulary, and reading comprehension skills. Journal of applied Developmental Psychology 31: 475-83. [CrossRef]

Lipka, Orly, Linda S. Siegel, and Rose Vukovic. 2005. The literacy skills of English language learners in Canada. Learning Disabilities Research and Practice 20: 39-49. [CrossRef]

Mancilla-Martinez, Jeannette, and Nonie K. Lesaux. 2010. Predictors of reading comprehension for struggling readers: The case of Spanish-speaking language minority learners. Journal of Educational Psychology 102: 701. [CrossRef]

Marinis, Theodoros, and Sharon Armon-Lotem. 2015. Sentence repetition. In Assessing Multilingual Children: Disentangling Bilingualism from Language Impairment 95-124.S. Edited by Sharon Armon-Lotem, Jan de Jong and Natalia Meir. Clevendon: Multilingual Matters.

Melby-Lervåg, Monica, and Arne Lervåg. 2014. Reading comprehension and its underlying components in second-language learners: A meta-analysis of studies comparing first-and second-language learners. Psychological Bulletin 140: 409. [CrossRef]

Montrul, Silvina. 2016. The Acquisition of Heritage Languages. Cambridge: Cambridge University Press.

Nakamoto, Jonathan, Kim A. Lindsey, and Franklin R. Manis. 2007. A longitudinal analysis of English language learners' word decoding and reading comprehension. Reading and Writing 20: 691-719. [CrossRef]

Nation, Kate, and Margaret J. Snowling. 2004. Beyond phonological skills: Broader language skills contribute to the development of reading. Journal of Research In Reading 27: 342-56. [CrossRef]

Oakhill, Jane V., and Kate Cain. 2012. The precursors of reading ability in young readers: Evidence from a four-year longitudinal study. Scientific Studies of Reading 16: 91-121. [CrossRef]

Ouellette, Gene P. 2006. What's meaning got to do with it: The role of vocabulary in word reading and reading comprehension. Journal of Educational Psychology 98: 554. [CrossRef]

Ouellette, Gene P., and Ashley Beers. 2010. A not-so-simple view of reading: How oral vocabulary and visual-word recognition complicate the story. Reading and Writing 23: 189-208. [CrossRef]

Paradis, Johanne. 2010. The interface between bilingual development and specific language impairment. Applied psycholinguistics 31: 227-52. [CrossRef]

Paradis, Johanne. 2011. Individual differences in child English second language acquisition: Comparing child-internal and childexternal factors. Linguistic Approaches to Bilingualism 1: 213-37. [CrossRef]

Pearson, Barbara Z., Sylvia C. Fernandez, Vanessa Lewedeg, and D. Kimbrough Oller. 1997. The relation of input factors to lexical learning by bilingual infants. Applied Psycholinguistics 18: 41-58. [CrossRef]

Peets, Kathleen F., Odilia Yim, and Ellen Bialystok. 2019. Language proficiency, reading comprehension and home literacy in bilingual children: The impact of context. International Journal of Bilingual Education and Bilingualism 24: 1-15. [CrossRef]

Perfetti, Charles A., and Susan Dunlap. 2008. Learning to Read: General principles and Writing System Variations. In Learning to Read across languages. London: Routledge, pp. 25-50.

Proctor, C. Patrick, María Carlo, Diane August, and Catherine Snow. 2005. Native Spanish-speaking children reading in English: Toward a model of comprehension. Journal of Educational Psychology 97: 246. [CrossRef]

Protopapas, Athanassios, Georgios D. Sideridis, Angeliki Mouzaki, and Panagiotis G. Simos. 2007. Development of lexical mediation in the relation between reading comprehension and word reading skills in Greek. Scientific Studies of Reading 11: 165-97. [CrossRef]

Protopapas, Athanassios, Panagiotis G. Simos, Georgios D. Sideridis, and Angeliki Mouzaki. 2012. The components of the simple view of reading: A confirmatory factor analysis. Reading Psychology 33: 217-40. [CrossRef]

Raven, J., J. C. Raven, and J. Court. 2004. Section 3: The Standard Progressive Matrices. In Manual for Raven's Progressive Matrices and Vocabulary Scales. San Antonio: Harcourt Assessment.

Rawson, Katherine A., and Walter Kintsch. 2005. Rereading effects depend on time of test. Journal of Educational Psychology 97: 70. [CrossRef]

Renfrew, Catherine E. 1995. Word Finding Vocabulary Test. Oxford: Speechmark Publishing.

Reyes, Iliana. 2012. Biliteracy among children and youths. Reading Research Quarterly 47: 307-27. [CrossRef]

Roth, Froma P, Deborah L. Speece, and David H. Cooper. 2002. A longitudinal analysis of the connection between oral language and early reading. The Journal of Educational Research 95: 259-72. [CrossRef]

Schwartz, Mila, David L. Share, Mark Leikin, and Ely Kozminsky. 2008. On the benefits of bi-literacy: Just a head start in reading or specific orthographic insights? Reading and Writing 21: 905-27. [CrossRef]

Seymour, Philip H., Mikko Aro, Jane M. Erskine, and collaboration with COST Action A8. 2003. Foundation literacy acquisition in European orthographies. British Journal of Psychology 94: 143-74. [CrossRef]

Snowling, Margaret, Susan E. Stothard, Paula Clarke, Claudine Bowyer-Crane, Angela Harrington, Emma Truelove, K. Nation, and Charles Hulme. 2009. York Assessment of Reading for Comprehension-Passage Reading. Brentford: GL Assessment.

Speece, Deborah L., Kristen D. Ritchey, David H. Cooper, Froma P. Roth, and Christopher Schatschneider. 2004. Growth in early reading skills from kindergarten to third grade. Contemporary Educational Psychology 29: 312-32. [CrossRef]

Statistics at Department for Education. 2019. Available online: https:/ / www.gov.uk/government/organisations/department-foreducation/about/statistics (accessed on 10 December 2020).

Sénéchal, Monique. 2006. Testing the home literacy model: Parent involvement in kindergarten is differentially related to grade 4 reading comprehension, fluency, spelling, and reading for pleasure. Scientific Studies of Reading 10: 59-87. [CrossRef] 
Sénéchal, Monique, and Jo-Anne LeFevre. 2002. Parental involvement in the development of children's reading skill: A five-year longitudinal study. Child Development 73: 445-60. [CrossRef] [PubMed]

Thordardottir, Elin. 2011. The relationship between bilingual exposure and vocabulary development. International Journal of Bilingualism 15: 426-45. [CrossRef]

Torgesen, Joseph K., Carol Alexander Rashotte, and Richard K. Wagner. 1999. TOWRE: Test of Word Reading Efficiency. Austin: Psychological Corporation Toronto.

Tobia, Valentina, and Paola Bonifacci. 2015. The simple view of reading in a transparent orthography: The stronger role of oral comprehension. Reading and Writing 28: 939-57. [CrossRef]

Tuller, Laurice. 2015. 11 Clinical Use of Parental Questionnaires in Multilingual Contexts. Assessing Multilingual Children: Disentangling Bilingualism from Language Impairment 13: 301.

Tunmer, William E., and James W. Chapman. 2012. The simple view of reading redux: Vocabulary knowledge and the independent components hypothesis. Journal of Learning Disabilities 4: 453-66. [CrossRef] [PubMed]

Van Steensel, Roel. 2006. Relations between socio-cultural factors, the home literacy environment and children's literacy development in the first years of primary education. Journal of Research in Reading 29: 367-82. [CrossRef]

Vellutino, Frank R., William E. Tunmer, James J. Jaccard, and RuSan Chen. 2007. Components of reading ability: Multivariate evidence for a convergent skills model of reading development. Scientific Studies of Reading 11: 3-32. [CrossRef]

Verhoeven, Ludo. 2000. Components in early second language reading and spelling. Scientific Studies of Reading 4: 313-30. [CrossRef]

Verhoeven, Ludo, and Jan Van Leeuwe. 2012. The simple view of second language reading throughout the primary grades. Reading and Writing 25: 1805-18. [CrossRef]

Vogindroukas, I., A. Protopapas, and G. Sideridis. 2009. Test of Expressive Vocabulary. Chania: Glafki. 